\title{
Imobilização da celulase presente em caldo fermentado em um suporte a base de quitosana
}

Immobilization of cellulase present in the fermentation broth on a support base chitosan

J. Nascimento de Jesus; P. A. W. Cavalcante; C. M. S. Almeida; T. S. de

Oliveira1; V. S. Varandas; D. F. Coêlho; J. R. S. Rodrigues; R. R. de Souza

Departamento de Engenharia Química, Laboratório de Biotecnologia Ambiental (LABAM), Universidade Federal de Sergipe, 49100-000, São Cristóvão-Sergipe, Brasil.

*rrsouza@ufs.br

(Recebido em 22 de julho de 2017; aceito em 25 de maio de 2018)

As celulases são enzimas responsáveis pela hidrólise da celulose e apresentam um potencial crescente no mercado mundial. Neste experimento, foi utilizado o caldo bruto da celulase com uma atividade inicial de $2520 \mathrm{U} / \mathrm{kg}$ para imobilização em esferas de quitosana, usando como agente ativador o glutaraldeído. Foram estudados os efeitos da quantidade do caldo bruto, da quantidade das esferas e do agente ativador sobre o rendimento de imobilização, a atividade do biocatalisador e o sobrenadante do processo. Os melhores resultados obtidos levaram a escolha do volume e da quantidade de esferas para última fase, respectivamente de $7 \mathrm{~mL}$ e 14 esferas. Em relação à presença do agente ativador, o melhor resultado obtido foi o terceiro caso, no qual ocorreu a adsorção e depois foi adicionado o glutaraldeído e imobilizado novamente, apresentando $53,6 \%$ como rendimento de imobilização, 9,3\% de atividade recuperada, $1180 \mathrm{U} / \mathrm{kg}$ de atividade no sobrenadante e uma atividade no biocatalisador de $124,2 \mathrm{U} / \mathrm{kg}$.

Palavras-chave: Imobilização, Celulase, Quitosana

Cellulases are enzymes responsible for the hydrolysis of cellulose and an enzyme with increasing potential in the world market. In this experiment, the crude broth of cellulase with an initial activity of $2520 \mathrm{U} / \mathrm{kg}$ was used for immobilization in chitosan beads, using glutaraldehyde as the activating agent. The effects of the amount of the crude broth, the amount of the beads and the activating agent, the immobilization yield, the biocatalyst activity and the supernatant were studied. The best results obtained led to the choice of the volume and quantity of spheres for the last phase, respectively of $7 \mathrm{~mL}$ and 14 spheres. Regarding the presence of the activating agent, the best result was the third case, where the adsorption occurred and then the glutaraldehyde and immobilized were added again, presenting 53.6\% as immobilization yield, 9.3\% recovered activity, $1180 \mathrm{U} / \mathrm{kg}$ activity in the supernatant and a biocatalyst activity of $124.2 \mathrm{U} / \mathrm{kg}$. Keywords: Cellulase, Immobilization, Chitosan.

\section{INTRODUÇÃO}

As enzimas são proteínas com um alto poder catalítico que aceleram as reações químicas, ou seja, são catalisadores biológicos. Com exceção de um pequeno grupo de moléculas de RNA, enzimas, em sua maioria, são proteínas constituídas por grandes cadeias de aminoácidos que se formam por ligação peptídica. Sua atividade catalítica depende da integridade conformacional da proteína ativa, isto é, ela perde sua atividade caso sofra alterações, por exemplo, se ela for quebrada em aminoácidos, sua atividade catalítica será sempre destruída $[1,2]$.

A enzima celulase apresenta uma vasta gama de usos em diversas indústrias, incluindo biocombustíveis e celulósica. Esta enzima é capaz de despolimerizar as cadeias celulósicas no substrato lignocelulósico para produzir celobiose e glicose [3,4]. Embora possa ser produzida por fermentação submersa, a maioria dos estudos relata sua produção pela fermentação em estado sólido, utilizando fungos ou bactérias, uma vez que o processamento é simplificado e apresenta risco reduzido de contaminação [5]. Ainda que as celulases apresentem inúmeras aplicações industriais, o alto custo de aquisição pode tornar o processo enzimático inviável. Nesse contexto, a imobilização propicia uma maior economia industrial em virtude da possibilidade de reuso das 
mesmas. Dentre os suportes utilizados para imobilização de celulases, destacam-se a agarose, a sílica gel, a quitosana, as partículas de grafeno, a acrilamida, entre outros [3].

Devido a esses problemas encontrados nos catalisadores químicos, a capacidade catalítica das enzimas as tornam adequadas para aplicações industriais, ligada ao fato que as enzimas operam em condições de reações amenas, como pressão atmosférica, temperaturas próximas à do ambiente e $\mathrm{pH}$ neutro atraiu muitos pesquisadores e indústrias para o desenvolvimento de artifícios utilizando esses catalisadores $[4,5]$.

Os problemas encontrados na utilização de enzimas residem na dificuldade de recuperação no término da catálise, instabilidade para a sua utilização em determinados solventes e/ou condições de $\mathrm{pH}$, temperatura e a exposição a agentes desnaturantes. Nas enzimas de forma solúvel, a principal desvantagem é a sua separação para depois aplicação, assim como contaminação do produto final. Deste modo, o uso de técnicas de imobilização é importante para estabilização e redução da inativação por distorções da sua estrutura nativa por influência de solventes orgânicos, $\mathrm{pH}$, temperatura [4-6].

Os métodos de imobilização geralmente dividem-se em químicos e físicos. Desses, ainda temse a classificação em 4 espécies: adsorção, ligação covalente, ligação cruzada e aprisionamento [7]. O método de ligação covalente é baseado na ligação forte entre o grupo amino das enzimas ao suporte, que sofrerá ativação do grupo ligante, através de um agente ativador, a fim de diminuir perdas da atividade enzimática [8]. Devido à presença de grupos aminos livres, os quais proporcionam maior solubilidade e reatividade entre a quitina e a celulase, a quitosana tem se mostrado um material em potencial utilizado na imobilização de celulases. Por ser um material bastante barato, é fundamental que se continue sua exploração como suporte para imobilização de enzimas [9].

O mercado mundial de enzimas está dividido em enzimas industriais: enzimas empregadas na produção de ração animal, enzimas empregadas na indústria de alimentos e enzimas técnicas (que são utilizadas na formulação de detergentes, produção de papel e celulose, manufatura de couros e produção de fármacos) e enzimas especiais (enzimas terapêuticas, enzimas para diagnóstico, enzimas para química quiral e enzimas para pesquisa). Destacam-se as enzimas dos ramos alimentícios e técnicas, sendo que essa última detém $50 \%$ do total de enzimas comercializadas [4, $10]$.

O presente trabalho tem o objetivo de estudar a atividade da celulase livre e imobilizada utilizando suporte de quitosana, glutaraldeído como ativador, analisando a variação de esfera, volume e tempo a fim de determinar as condições que proporcionem o melhor rendimento de imobilização.

\section{MATERIAL E MÉTODOS}

\subsection{Preparação do inóculo}

O microrganismo empregado na fermentação foi o fungo Aspergillus niger, o qual foi isolado do solo pelo Grupo de Engenharia de Sistemas Biológicos (BIOSE) da Universidade Federal do Rio de Janeiro e doado pelo Departamento de Tecnologia de Alimentos (DTA) da Universidade Federal de Sergipe (UFS). Para o preparo do inóculo, foram adicionados $50 \mathrm{~mL}$ da solução estéril de Tween 80 a $0,01 \%$ (v/v) aos frascos Erlenmeyers contendo os microrganismos no meio PDA (Potato Dextrose Agar), com o intuito de soltar os esporos. Logo após, a suspensão de esporos foi colocada em um frasco esterilizado e armazenada a $4{ }^{\circ} \mathrm{C}$.

\subsection{Preparação do Extrato Enzimático}

As fermentações em estado sólido foram realizadas em frascos Erlenmeyers de $250 \mathrm{~mL}$, contendo 7,5 g de sabugo de milho e o volume da solução nutriente suficiente para atingir $55 \%$ de umidade, com pH inicial de 5,5. A solução nutriente era composta por: $\left(\mathrm{NH}_{4}\right)_{2} \mathrm{SO}_{4}, 10 \mathrm{~g} / \mathrm{L} ; \mathrm{KH}_{2} \mathrm{PO}_{4}$, $3 \mathrm{~g} / \mathrm{L} ; \mathrm{MgSO}_{4} .7 \mathrm{H}_{2} \mathrm{O}, 0,5 \mathrm{~g} / \mathrm{L} ; \mathrm{CaCl}_{2}, 0,5 \mathrm{~g} / \mathrm{L} ; \mathrm{FeSO}_{4} .7 \mathrm{H}_{2} \mathrm{O}, 0,005 \mathrm{~g} / \mathrm{L} ; \mathrm{MnSO}_{4} . \mathrm{H}_{2} \mathrm{O}, 0,0016 \mathrm{~g} / \mathrm{L} ;$ 
$\mathrm{ZnSO}_{4} .7 \mathrm{H}_{2} \mathrm{O}, 0,0014 \mathrm{~g} / \mathrm{L}$. Os frascos foram esterilizados em autoclave a $121{ }^{\circ} \mathrm{C}$ e 1 atm durante 15 minutos. Após o resfriamento, o meio foi inoculado com o volume de suspensão necessário para obter a concentração final de $2 \cdot 10^{7}$ esporos por grama de substrato sólido (sabugo de milho) e, posteriormente, incubado a $30^{\circ} \mathrm{C}$ por um período de $120 \mathrm{~h}$. Ao final da fermentação, as enzimas celulolíticas foram extraídas a partir do caldo fermentado.

Em cada Erlenmeyer, adicionou-se água destilada na razão 1:10 (m/v) e misturou-se em um agitador orbital a $120 \mathrm{rpm}$ e $30^{\circ} \mathrm{C}$ durante 1 hora. Em seguida, o extrato enzimático foi filtrado a vácuo. Os extratos obtidos foram centrifugados a $800 x \mathrm{xG}$ durante 15 minutos e o sobrenadante foi utilizado como fonte de enzima extracelular.

\subsection{Preparação das esferas como Suporte para imobilização-Quitosana}

Utilizou-se como suporte para imobilização esferas de quitosana. A produção das esferas foi realizada através da pesagem de $1 \mathrm{~g}$ de quitosana em pó e sua dissolução em $30 \mathrm{~mL}$ de solução de ácido acético $(5 \%)$. Através de uma bomba, essa solução foi aspergida gota a gota em uma solução de $\mathrm{NaOH} 1 \mathrm{M}$ que estava em agitação, formando as esferas de quitosana (Figura 1), sendo em seguida lavadas e armazenadas em água destilada [11].

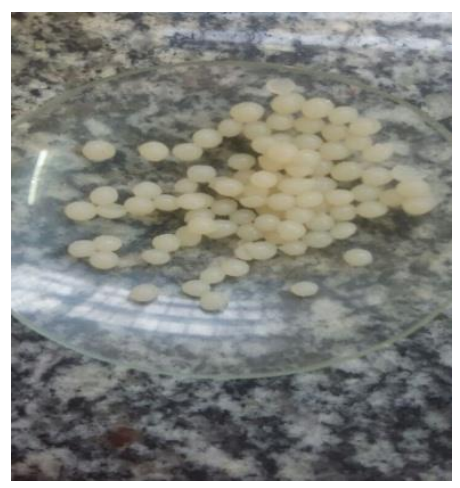

Figura 1: Esferas de quitosana.

\subsection{Preparação do Agente Ativador e Ativação do Suporte}

$\mathrm{O}$ agente ativador, glutaraldeído (3\%), foi utilizado para ativação das esferas de quitosana. $\mathrm{Na}$ ativação do suporte, foram adicionadas em um béquer esferas de quitosana e $30 \mathrm{~mL}$ de uma solução de glutaraldeído (3\%), e ficaram 24 horas sob agitação em um shaker a 120 rpm. Após esse tempo, as esferas ativadas (Figura 2) foram lavadas com tampão fosfato $\mathrm{pH}$ 7,0 para eliminar o excesso de glutaraldeído [11].

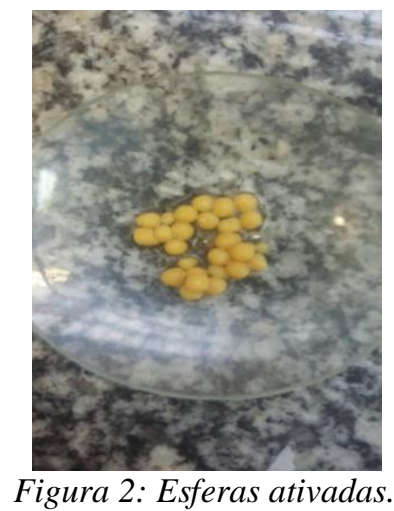




\subsection{Imobilização da Celulase em Quitosana}

Após ativação das esferas de quitosana, o caldo enzimático foi imobilizado. O processo de imobilização ocorreu com a adição das esferas ativadas e o caldo bruto em um béquer de $100 \mathrm{~mL}$, no qual ficaram por 24 horas sob agitação em um shaker com $120 \mathrm{rpm}$. Após esse período, as esferas foram lavadas com tampão fosfato $\mathrm{pH} \mathrm{7,0}$ para remoção das enzimas, em seguida, quantificar o valor da atividade enzimática do biocatalisador (esfera-enzima) e do sobrenadante.

\subsection{Determinação da Curva Padrão de Glicose para Determinar a Concentração dos Açucares Redutores}

A partir da solução de glicose preparada, foram feitas 5 diluições com tampão citrato de sódio $0,05 \mathrm{M} \mathrm{pH} \mathrm{4,8}$, nas concentrações $6,7 \mathrm{~kg} / \mathrm{m}^{3}, 5,0 \mathrm{~kg} / \mathrm{m}^{3}, 3,3 \mathrm{~kg} / \mathrm{m}^{3} \mathrm{e} 2,0 \mathrm{~kg} / \mathrm{m}^{3}$, sendo preparada uma curva padrão através dos valores das absorbâncias obtidas. A curva foi utilizada para quantificar as concentrações de açúcares redutores utilizando o método DNS (ácido 3,5dinitrosalicílico) [13].

\subsection{Determinação da Atividade Enzimática}

O método utilizado para determinação da atividade enzimática da celulase foi a hidrólise do papel filtro conforme metodologia de Ghose (1987) [12].

$\mathrm{O}$ experimento foi realizado com 3 tubos de ensaio. $\mathrm{O}$ primeiro tubo foi denominado de espectro e dentro dele foram adicionados $1,5 \mathrm{~mL}$ de tampão citrato $\mathrm{pH} 4,8$. O segundo tubo foi denominado de branco, contendo $1 \mathrm{~mL}$ de tampão e, por fim, o terceiro tubo, denominado de amostra, contendo $1 \mathrm{~mL}$ de tampão, e o substrato, uma tira de papel filtro $(1,0$ por $6,0 \mathrm{~cm})$.

Os 3 tubos foram levados ao banho por 300s e, após esse tempo, foram adicionados $0,5 \mathrm{~mL}$ do caldo no tubo denominado de amostra e todos os 3 foram levados à incubação por $50 \mathrm{~min}$.

Após o período de incubação, foram adicionados $0,5 \mathrm{~mL}$ de caldo bruto inativado no branco e, posteriormente, $3 \mathrm{~mL}$ de DNS nos 3 tubos, colocando-os para aquecer por 300s. Em seguida, foram completados com $20 \mathrm{~mL}$ de água destilada e colocados para esfriar por 1200s e, assim, realizadas as leituras de absorbâncias no comprimento de $540 \mathrm{~nm}$.

Os cálculos das atividades enzimáticas foram feitos de acordo com as instruções de Ghose (1987) [12].

\subsection{Cálculo do Rendimento de Imobilização e da Atividade Recuperada}

O estudo da imobilização foi feito através de dois fatores: rendimento de imobilização, apresentado na equação 1 e atividade recuperada, apresentada na segunda equação 2 .

$$
\begin{aligned}
& \text { Rendimento de imobilização }(\%)=\left(\frac{\text { atividade do caldo bruto }- \text { atividade do sobrenadante }}{\text { atividade do caldo bruto }}\right) 100 \\
& \text { Atividade recuperada }(\%)=\left(\frac{\text { atividade do biocatalisador }}{\text { atividade do caldo bruto }- \text { atividade do sobrenadante }}\right) 100
\end{aligned}
$$

\subsection{Influência do Volume do Caldo Bruto na Imobilização da Celulase}

A primeira parte deste estudo foi verificar a influência do volume do caldo bruto na imobilização e foram fixados 10 biocatalisadores (enzima-suporte) para cada volume testado.

Primeiramente, foram utilizados $10 \mathrm{~mL}$ do caldo bruto para imobilização por 24 horas e, após esse período, foram feitas as medidas das atividades enzimáticas no sobrenadante e no biocatalisador, conforme metodologia descrita no item 2.6. Essa atividade foi calculada a partir da equação da reta da curva padrão e pelas instruções de Ghose (1987) [12]. Esse mesmo procedimento foi repetido para o volume de $7 \mathrm{~mL}$. 


\subsection{Influência da Quantidade de Biocatalisadores na Imobilização}

Após definir o volume a ser utilizado para as próximas etapas do experimento $(7 \mathrm{~mL})$, foram realizados testes com 7, 10 e 14 esferas, a fim de conseguir o maior rendimento de imobilização.

\subsection{Influência do Glutaraldeído no Processo de Imobilização}

A última parte do experimento foi baseada na importância do glutaraldeído na imobilização, e para tal foram feitos 3 testes, uma imobilização por adsorção, sem a presença de glutaraldeído, uma imobilização com a presença do agente ativador (glutaraldeído) e uma imobilização com adsorção e ativação.

\section{RESULTADOS E DISCUSSÃO}

A imobilização da celulase por meio da ligação covalente entre a enzima e o suporte sólido iniciou-se através da preparação das esferas de quitosana. Em seguida, o agente entrecruzante, o glutaraldeído, foi empregado no processo de ativação das esferas. O glutaraldeído foi responsável por provocar um afastamento do grupo aldeído da superfície do suporte para que se tornasse fortemente eletrofílico e se ligasse ao grupo amina da enzima, ocasionando uma modificação química garantindo ao suporte uma maior resistência a mudanças conformacionais induzidas por agentes desnaturantes $[1,11,15]$.

Os parâmetros estudados para a imobilização da celulase foram: o volume do caldo bruto (sem purificar), a quantidade de esferas e a adição do agente ativador - Glutaraldeído. Os quais serão tratados a seguir.

\subsection{Determinação da Concentração de Açúcares Redutores}

A curva padrão, com base nos dados mostrados na Figura 3 [12], foi preparada para o estudo dos açúcares redutores antes e após a imobilização e com isso foi possível o cálculo das atividades enzimáticas das amostras.

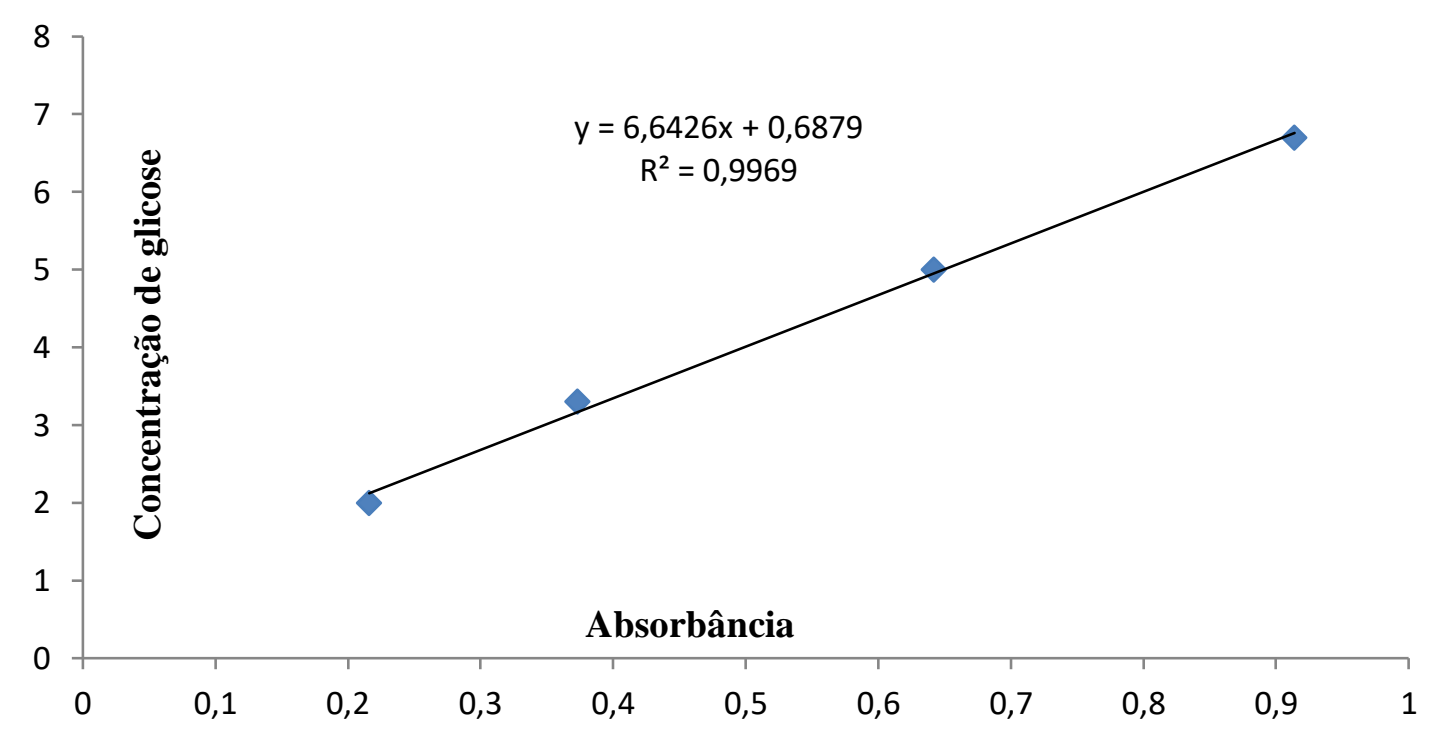

Figura 3: Curva Padrão de Glicose.

\subsection{Influência do Volume do Caldo Bruto na Imobilização da Celulase}

O objetivo dessa etapa foi estudar a influência que o volume do caldo bruto provocaria no rendimento de imobilização. 
Alguns trabalhos estudaram a variação do volume da enzima, como por exemplo Kumari e Kayastha (2011) [16], no qual o volume foi variado de $50 \mathrm{~mL}$ a $200 \mathrm{~mL}$ e, com isso, percebeu-se que o rendimento de imobilização no volume de $200 \mathrm{~mL}$ era praticamente igual ao rendimento de imobilização de $100 \mathrm{~mL}$.

A Tabela 1 apresenta os resultados das atividades enzimáticas, dos rendimentos de imobilização e da atividade recuperada.

Tabela 1: Atividade enzimática, rendimento de imobilização e atividade recuperada do caldo bruto do sobrenadante e do biocatalisador para 7 e $10 \mathrm{~mL}$.

\begin{tabular}{cccc}
\hline Amostra & $\begin{array}{c}\text { Atividade enzimática } \\
(\mathbf{U} / \mathbf{k g})\end{array}$ & $\begin{array}{c}\text { Rendimento de } \\
\text { imobilização (\%) }\end{array}$ & $\begin{array}{c}\text { Atividade } \\
\text { Recuperada (\%) }\end{array}$ \\
\hline $\begin{array}{c}\text { Caldo Bruto } \\
\text { Biocatalisador }^{\mathbf{a}}\end{array}$ & $\begin{array}{c}2520,0 \\
108,4\end{array}$ & N. A & N. A \\
Sobrenadante $^{\mathbf{a}}$ & 1730,0 & $31,34 \%$ & $13,7 \%$ \\
Biocatalisador $^{\mathbf{b}}$ & 117,0 & & \\
Sobrenadante $^{\mathbf{b}}$ & 1960,0 & $22,22 \%$ & $20,9 \%$ \\
\hline
\end{tabular}

$a=$ volume de $7 \mathrm{~mL}$ de caldo bruto para imobilização, $b=$ volume de $10 \mathrm{~mL}$ de caldo bruto para imobilização.

Observou-se na Tabela 1 que o caldo bruto apresentava uma atividade enzimática inicial de 2520 U/kg. Após a imobilização, com $7 \mathrm{~mL}$ e $10 \mathrm{~mL}$ de caldo bruto, percebeu-se um rendimento de imobilização respectivamente de $31,34 \%$ e $22,22 \%$, da enzima no suporte, mostrando que o volume do caldo não contribuiu para aumentar o rendimento de imobilização, mas isso se deve ao fato de que o caldo utilizado não era purificado.

O aumento do volume do caldo bruto provocou uma maior concentração de interferentes no caldo, fazendo com que o rendimento de imobilização para $10 \mathrm{~mL}$ diminuísse.

Notou-se que o biocatalisador ${ }^{\mathrm{a}}$ (enzima-suporte) apresentou uma atividade catalítica de 108,4 $\mathrm{U} / \mathrm{kg}$, enquanto o biocatalisador ${ }^{\mathrm{b}}$ apresentou uma atividade catalítica de 117,0 U/kg, apesar de ter imobilizado mais, a atividade catalítica do biocatalisador ${ }^{\mathrm{a}}$ foi inferior a obtida no biocatalisador ${ }^{\mathrm{b}}$, isso se deve ao fato de obstáculos estéricos que dificultaram o acesso do substrato aos sítios ativos das enzimas pela presença de inibidores, já que o caldo não foi purificado.

Em relação à atividade recuperada, atividade que o biocatalisador consegue recuperar da enzima livre, o que obteve maior resultado foi o biocatalisador $^{\mathrm{b}}$, apresentando $20,9 \%$.

Após essa etapa, foi definido o volume a ser utilizado para todo experimento, com isso, baseado em um maior rendimento o volume escolhido para próxima etapa foi o de $7 \mathrm{~mL}$.

\subsection{Influência da Quantidade de Esfera na Imobilização}

O objetivo dessa etapa foi verificar como a quantidade de esferas influenciou no rendimento de imobilização após fixação do volume, discutido no item 3.2.

A Tabela 2 apresenta os valores obtidos de atividade enzimática no sobrenadante e nos biocatalisadores, assim como o rendimento de imobilização e a atividade recuperada após imobilização.

Pode-se observar que o meio com 14 esferas apresentou o maior rendimento de imobilização $42,1 \%$, apresentou uma atividade recuperada de $10,34 \%$ e o sobrenadante ${ }^{c}$ apresentou uma atividade de 1460,0 U/kg. Isto era esperado, já que quanto maior o número de esferas maior a área de imobilização entre a enzima e o suporte.

No meio com 6 esferas, observou-se um maior rendimento de imobilização em relação ao meio com 10 esferas. Mesmo que esse fenômeno não seja o esperado, de acordo com Khan e Alzohairy (2010) [17], o processo de imobilização pode causar diferentes efeitos na atividade e seletividade da enzima. Problemas difusionais, que causam distorção da proteína e consequente perda de atividade, são comuns e somente são evitados através de um rígido controle das condições experimentais. Neste caso, no meio com 10 esferas, as enzimas da solução podem ter sido inativadas durante a imobilização, causando uma perda da atividade final do sobrenadante, resultando em um valor de rendimento inferior em relação ao de 6 esferas. 
Outro fator importante é a atividade do biocatalisador, percebeu-se que o biocatalisador ${ }^{\mathrm{c}}$ apresentou uma atividade catalítica de $109,7 \mathrm{u} / \mathrm{kg}$, o biocatalisador ${ }^{\mathrm{a}}$ apresentou uma atividade de $102,5 \mathrm{u} / \mathrm{kg}$ e o biocatalisador ${ }^{\mathrm{b}}$ apresentou uma atividade de 108,4 U/kg. Em termos de atividade no biocatalisador, não houve uma variação significativa, mas, em termos de rendimento de imobilização, percebeu-se uma variação significativa, tendo um rendimento de $42,1 \%$ para o meio com 14 esferas, mostrando que a adição de mais esferas disponibilizou mais sítios de imobilização aumentando assim o rendimento.

Tabela 2: Efeitos da quantidade de esferas no rendimento de imobilização e atividade recuperada.

\begin{tabular}{|c|c|c|c|}
\hline Amostra & $\begin{array}{c}\text { Atividade } \\
\text { Enzimática (U/kg) }\end{array}$ & $\begin{array}{l}\text { Rendimento de } \\
\text { Imobilização }\end{array}$ & $\begin{array}{c}\text { Atividade } \\
\text { Recuperada }(\%)\end{array}$ \\
\hline Caldo Bruto & 2520,0 & N.A & N. A \\
\hline $\begin{array}{l}\text { Biocatalisador } \\
\text { Sobrenadante }^{\mathrm{a}}\end{array}$ & $\begin{array}{c}102,5 \\
1630,0\end{array}$ & $35,3 \%$ & $11,5 \%$ \\
\hline $\begin{array}{l}\text { Biocatalisador } \\
\text { Sobrenadante }^{\mathrm{b}}\end{array}$ & $\begin{array}{c}108,4 \\
1730,0\end{array}$ & $31,3 \%$ & $13,7 \%$ \\
\hline $\begin{array}{l}\text { Biocatalisador }^{\mathrm{c}} \\
\text { Sobrenadante }^{\mathrm{c}}\end{array}$ & $\begin{array}{c}109,7 \\
1460,0\end{array}$ & $42,1 \%$ & $10,34 \%$ \\
\hline
\end{tabular}

Dessa forma, para a próxima etapa do experimento, foi utilizado o resultado que obteve a melhor eficiência na imobilização $(42,1 \%)$, visto que, em relação à atividade catalítica dos biocatalisadores, a variação não chegou a ser significativa.

\subsection{Influência da Adição do Glutaraldeído no Processo de Imobilização}

A Tabela 3 apresenta os valores obtidos de atividade enzimática no sobrenadante e no biocatalisador e a influência do agente ativador no processo de imobilização, assim como o rendimento de imobilização e a atividade recuperada após a imobilização.

Tabela 3: Efeito do glutaraldeído no rendimento de imobilização e Atividade recuperada.

\begin{tabular}{|c|c|c|c|}
\hline Amostra & $\begin{array}{c}\text { Atividade } \\
\text { enzimática }(U / \mathbf{k g})\end{array}$ & $\begin{array}{c}\text { Rendimento de } \\
\text { imobilização (\%) }\end{array}$ & $\begin{array}{c}\text { Atividade } \\
\text { Recuperada (\%) }\end{array}$ \\
\hline Biocatalisador $^{a}$ & 109,7 & $42,06 \%$ & $10,34 \%$ \\
\hline Sobrenadante ${ }^{a}$ & 1460,0 & & \\
\hline Biocatalisador $^{b}$ & 105,7 & $32,53 \%$ & $12,89 \%$ \\
\hline Sobrenadante $^{b}$ & 1700,0 & & \\
\hline Biocatalisador $^{c}$ & 124,2 & $53,17 \%$ & $9,26 \%$ \\
\hline Sobrenadante $^{c}$ & 1180,0 & & \\
\hline
\end{tabular}

Constatou-se que o melhor resultado foi para o processo de imobilização que teve a adsorção e, em seguida, a ligação covalente com o glutaraldeído, apresentando um rendimento de imobilização de $53,17 \%$ e uma atividade no biocatalisador ${ }^{\mathrm{c}}$ de $124,2 \mathrm{U} / \mathrm{kg}$, sendo os maiores valores em termos de rendimento e atividade encontrados neste experimento. Primeiramente ocorreu a adsorção física, mas não foi possível preencher completamente os sítios ativos, fazendo com que ao se ligar covalentemente com o glutaraldeído completasse os demais sítios disponíveis, obtendo assim uma maior imobilização da enzima no suporte.

$\mathrm{Na}$ imobilização, que teve somente a adsorção, verificou-se o menor rendimento de imobilização, isso porque a esfera não tem porosidade suficiente para que ocorra a adsorção, e a enzima não se liga espontaneamente ao suporte sem a presença do glutaraldeído.

O processo de adsorção física é baseado na atração das forças de van der Waals entre a enzima e a superfície do suporte, que são forças fracas, permitindo a dessorção da enzima durante a utilização. Sendo assim, esse processo pode provocar a inativação da atividade catalítica do biocatalisador [14]. 
No processo que teve imobilização por ligação covalente (presença de glutaraldeído), o rendimento de imobilização foi de 42,06\%. Cruz Júnior (2007) [11], que em seu trabalho estudou a variação da concentração de glutaraldeído e como o aumento da concentração afetava o processo de imobilização, percebeu que há uma melhor eficiência da ligação covalente entre a enzima e o suporte quando a concentração de glutaraldeído estiver na faixa de 1 a 3\%. Nesse experimento, a concentração de glutaraldeído foi de $3 \%$.

Percebeu-se que as enzimas no caldo bruto foram imobilizadas, já que a atividade enzimática no sobrenadante era menor que a atividade inicial e os biocatalisadores apresentaram atividades, porém a atividade enzimática do biocatalisador foi inferior a atividade enzimática do caldo bruto antes de imobilizada, o que não é o esperado quando se compara com os resultados da literatura. Segundo Vargas (2014) [15], um dos objetivos da imobilização é manter a atividade catalítica de forma que não haja diminuição ao longo do processo.

Mubarak et al. (2014) [7] obtiveram nos resultados do seu experimento que a enzima celulase imobilizada mostrou uma atividade significativamente maior do que na atividade da enzima livre. A razão para o ocorrido deve-se ao fato de que a enzima utilizada não era pura, ou seja, a presença de interferentes no caldo bruto contribuiu para uma baixa atividade enzimática após imobilização. Tais interferentes decorrem do preparo das enzimas durante o processo de fermentação, no qual foi empregado como fonte de carbono o resíduo sólido do milho, isto é, o sabugo.

\section{CONCLUSÃo}

O processo de imobilização foi capaz de imobilizar a celulase presente no caldo bruto enzimático, observando-se o efeito do volume do caldo, quantidade de esferas e a presença do agente ativador, no rendimento de imobilização.

O melhor resultado foi obtido no processo de imobilização em que primeiro ocorre a adsorção e depois as ligações covalentes na presença do glutaraldeído. Tal processo foi capaz de obter rendimento de imobilização de $53.17 \%$, com uma atividade recuperada de $9,26 \%$ e uma atividade no biocatalisador de $124,2 \mathrm{U} / \mathrm{kg}$.

Deste modo, este trabalho demonstrou que o processo de imobilização enzimática pode ser realizado em caldos brutos não purificados e, desta forma, eliminando a necessidade de uma etapa de purificação preliminar. Além disso, demonstrou-se que o volume de extrato enzimático e número de esferas utilizadas afetam significativamente a imobilização e subsequentemente tornam necessário o estudo de cada processo de imobilização para estabelecer as condições ótimas do processo.

\section{AGRADECIMENTOS}

Os autores gostariam de agradecer a CAPES e CNPq pelo suporte financeiro e concessão de bolsas.

\section{REFERÊNCIAS BIBLIOGRÁFICAS}

1. Martins RE. Estudo da imobilização de celulase em géis de quitosana [Mestrado]. São Carlos - SP: Universidade Federal de São Carlos; 2010.

2. Lehninger AL, Nelson DL, Nelson DL, Cox MM. Lehninger principles of biochemistry. New York: W.H. Freeman; 2008.

3. El-Ghaffar MAA, Hashem MS. Chitosan and its amino acids condensation adducts as reactive natural polymer supports for cellulase immobilization. Carbohydr Polym. 2010;81(3):507-16, doi:https://doi.org/10.1016/j.carbpol.2010.02.025.

4. Mendes AA, Oliveira P, Castro H, Giordano R. Aplicação de quitosana como suporte para a imobilização de enzimas de interesse industrial. Quim Nova. 2011;34(5):831-40, doi:10.1590/S010040422011000500019 .

5. Fernandes K, Lima C, Lopes F. Técnicas de Imobilização de Enzimas. Revista Processos Químicos. 2010:53-8. 
6. Canilha L, Carvalho W, Silva J. Biocatalisadores imobilizados: uso de células e enzimas imobilizadas em processos biotecnológicos. Biotecnologia, Ciência e Desenvolvimento, Brasília. 2006(36):48-57.

7. Mubarak N, Wong J, Tan K, Sahu J, Abdullah E, Jayakumar N, et al. Immobilization of cellulase enzyme on functionalized multiwall carbon nanotubes. J Mol Catal B: Enzym. 2014;107:124-31, doi:10.1016/j.molcatb.2014.06.002.

8. Elba P. Enzimas em biotecnologia: produção, aplicações e mercado: Interciência; 2008.

9. Monteiro OAC, AiroldI C. Some studies of crosslinking chitosan-glutaraldehyde interaction in a homogeneous system. Int J Biol Macromol. 1999;26(2):119-28.

10. Monteiro VN, Silva R. Aplicações industriais da biotecnologia enzimática. Revista Processos Químicos. 2009;3(5):9-23.

11. Cruz Júnior A. Imobilização de lipase de Candida antarctica B em quitosana para obtenção de biodiesel por transesterificação do óleo de mamona [Mestrado]. Florianópolis, SC: Universidade Federal de Santa Catarina; 2007.

12. Ghose TK. Measurement of cellulase activities. Pure Appl Chem. 1987;59(2):257-68, doi:10.1351/pac198759020257.

13. Miller GL. Use of dinitrosalicylic acid reagent for determination of reducing sugar. Anal Chem. 1959;31(3):426-8, doi:10.1021/ac60147a030.

14. Messing R. Immobilized enzymes for industrial reactors: Elsevier; 2012.

15. VargaS NG. Comparação das atividades enzimáticas de $\alpha$-amilase livre e imobilizada em suporte de quitosana. Alegre: Universidade Federal do Espírito Santo; 2014.

16. Kumari A, kayastha AM. Immobilization of soybean (Glycine max) $\alpha$-amylase onto Chitosan and Amberlite MB-150 beads: Optimization and characterization. J Mol Catal B: Enzym. 2011;69(1-2):8-14, doi:10.1016/j.molcatb.2010.12.003.

17. Khan AA, Alzohairy MA. Recent advances and applications of immobilized enzyme technologies: A review. Res J Biol Sci. 2010;5(8):565-75. 